\title{
Courrier
}

\section{Gasetta dals medis svizzers}

Sehr geehrte Kolleginnen und Kollegen der SÄZ

Probieremer's nomol ...

Vor Jahren habe ich schon einmal ein Herzensanliegen vorgebracht, unser Vereinsorgan, die löbliche "Schweizerische Ärztezeitung» auf dem Titelblatt auch mit der vierten Landessprache, dem Rätoromanischen, zu schmücken. Der Zusatz, "Gasetta dals medis svizzers», würde dem "Outfit» gut anstehen.

Als Einzeltäter mit akklamativem Support des Engadiner und Bündner Ärztevereins wurde mein Anliegen damals schnöde und kurz abgeblockt als Etikettenschwindel, komme die romanische Sprache im redaktionellen Teil doch nicht vor!!! (Wie steht's mit dem Italienischen?)

Nochmals: Der Erhalt der rätoromanischen Sprache liegt mir am Herzen. Die Ergänzung mit "Gasetta dals medis svizzers» wäre nicht nur eine Reanimations- oder wenigstens eine lindernde Palliations-Massnahme, sondern eine uns sicher zustehende Zurkenntnisnahme!

Grazcha fich e cordiels salüds

\section{Dr. med. Gian Bieler, Samedan}

Anmerkung der Redaktion: Eine Ergänzung, wie sie von Kollege Bieler angeregt wird, liegt nicht in der Kompetenz der Redaktion oder des Schweizerischen Ärzteverlags EMH Media, sondern müsste bei den zuständigen Gremien der FMH beantragt werden.

\section{Kommunikationsunterschiede} zwischen Schweizern und Deutschen

Kommentar zu «Der kleine Unterschied» [1] Vor einiger Zeit thematisierten Sie in Ihrer Zeitschrift «die wichtigsten Mentalitäts- und Sprachunterschiede zwischen Schweizern und
Deutschen». Als Autorin von «Deutsche in der Schweiz suchen Heilung - Was Demokratie vom Einzelnen fordert und wie Prägungen aus der Vergangenheit dabei im Wege stehen können" [2014] habe ich mich mit der Situation der Deutschen in der Schweiz eingehend befasst.

Zugewanderte halten sich freiwillig in dem ihnen unbekannten Land auf. Sie sind Gäste in einem fremden Haushalt. Lassen sie es an Anerkennung und Respekt gegenüber ihren Gastgebern und deren Verhältnissen fehlen, dürfen sie sich in der Folge über eventuelle Schwierigkeiten nicht beklagen. Es ist an den deutschen Immigrierten, in der Schweiz die üblichen Integrationsschritte zu unternehmen.

Es gilt als unabdingbar für eine gelungene Integration, dass Zugewanderte im gewählten Land die Umgangssprache lernen. Das hat auch für die Bundesbürger in der Deutschschweiz Gültigkeit, trotz oft gegenteiliger Ansicht. Sie kommen nicht darum herum, sich einen schweizerischen Dialekt anzueignen, das heisst, sowohl Hörverständnis als auch Sprechkompetenz einer Mundart zu erwerben. Denn Mundart ist die hiesige Umgangssprache - nicht Hochdeutsch! Diesen natürlichen Akt der Wertschätzung unterlassen die meisten Deutschen.

Wenn man als Migrantin inmitten einer kulturell anders sozialisierten Bevölkerung lebt, kommt man nicht darum herum, die innere Einstellung anzupassen. Doch Bundesbürgerinnen und -bürger fühlen sich gegenüber uns Schweizern gerne überlegen - eine Haltung, die eine senkrechte Denkweise erkennen lässt. Diese entstammt der mittelalterlichen Ständeordnung und hat dem Nationalsozialismus als Grundlage gedient. In einer Demokratie ist die Auffassung einer Zwei-KlassenGesellschaft nicht angebracht. Wir zutiefst demokratisch eingestellten Schweizer sind von der Gleichheit und Würde aller Menschen überzeugt, wir denken horizontal. Deshalb kennen wir auch die von Ihnen empfohlene «Unterwürfigkeit» nicht. Wir stehen nebeneinander - wie es sich für Demokratin- nen und Demokraten gehört. Die senkrechte Denkweise ist überholt.

In Ihrem Artikel bringen Sie Beispiele von Kritik. Deutsche glauben, mit ihrer «direkten Art» sachbezogen zu argumentieren: «Du hast einige grobe Fehler gemacht» und «Sie haben die Anforderung komplett verfehlt.» Aber eine derart negative Quantifizierung gibt ein mögliches Fehlverhalten nicht realistisch wieder. Damit greift eine deutsche Person das Gegenüber nur an, man merkt: Sie liebt es, jemanden zu massregeln! Im Gegensatz dazu sind die schweizerischen Beispiele lösungsorientiert: «Mir söttet no einisch zämecho u das Manuskript dürrego.» Der Hinweis: «I gloube, da heimer d Möglichkeit, viel meh ussezhole» betont, dass Raum für Verbesserungen da ist. So legt der Deutsche hier Wert auf das Fehlerhafte - ohne den Mangel zu beheben. Ihm fällt vor allem das Defizit der andern Person auf. Die Schweizerin mit ihrer indirekten Art jedoch richtet ihr Augenmerk auf den Teil, der noch zu verbessern ist, sie schaut auf die Möglichkeiten. Ihr ist das Potential der andern Person wichtig. Zudem bietet sie ihr ihre Hilfe an. - Nur der schweizerische Sprachstil ist demokratiekompatibel und berücksichtigt die Menschenwürde. Denn einzig wertschätzendes Kommunizieren und lösungsorientiertes Handeln bringen eine friedensstiftende Begegnungskultur hervor.

Ma Gyan Sevanti Weber, Bern

1 Diehm N, Baumann F, Pill I. Der kleine Unterschied. Schweiz Ärztezeitung.2013;94(1/2):31-3.

\section{Lettres de lecteurs}

Envoyez vos lettres de lecteur de manière simple et rapide. Sur notre site internet, vous trouverez un outil spécifique pour le faire. Votre lettre de lecteur pourra ainsi être traitée et publiée rapidement. Vous trouverez toutes les informations sous: www.bullmed.ch/auteurs/

envoi-lettres-lecteurs/ 